\title{
Fonsecaea pedrosoi as a rare cause of acute conjunctival ulceration
}

\author{
Fonsecaea pedrosoi como agente raramente associado à úlcera conjuntival aguda
}

Fatil Mehmet Adibelli ${ }^{1}$, Nilgun Karabicak ${ }^{2}$, Ali Akal ${ }^{1}$, Tugba Goncu ${ }^{1}$, Omer Faruk Yilmaz ${ }^{1}$, Mehmet Bayraktar ${ }^{3}$

\begin{abstract}
Conjunctival ulceration accompanied with secretion and pain was observed in a 30-year-old male, 3 days after a perforating corneal trauma. Cultures of conjunctival ulcer samples grew Fonsecaea pedrosoi, a major causative agent of chromoblastomycosis that is typically transmitted during trauma. The conjunctival ulcer was successfully treated with amphotericin B, itraconazole, and fluconazole. This case report summarizes the diagnosis and treatment of a conjunctival ulcer due to F. pedrosoi, which is a rare complication of contaminated ocular trauma. To the best of our knowledge, this is the first reported case of F. pedrosoi causing acute conjunctival ulceration in the literature.
\end{abstract}

Keywords: Chromoblastomycosis; Ascomycota/isolation \& purification; Conjunctival disease; Eye injuries, penetrating; Eye infections, fungal

\begin{abstract}
RESUMO
O quadro clínico de uma úlcera conjuntival acompanhada de secreção e dor foi observado em homem de 30 anos de idade, 3 dias após um trauma perfurante da córnea. As culturas de uma amostra retirada da úlcera conjuntival foi positiva para Fonsecaea pedrosoi, uma cromoblastomicose, geralmente transmitido após traumatismos. O caso foi tratado com sucesso com a anfotericina $B$, itraconazol e fluconazol. Este relato de caso reporta o diagnóstico e tratamento de uma úlcera conjuntival causada por $\mathrm{F}$. pedrosoi, que raramente é visto nos olhos expostos a traumatismos contaminados. Até onde sabemos, este é o primeiro caso relatado na literatura de F. pedrosoi causando úlcera conjuntival aguda.
\end{abstract}

Descritores: Cromoblastomicose; Ascomycetos/isolamento \& purificação; Doenças da túnica conjuntiva; Ferimentos oculares penetrantes; Infecções oculares fúngicas

\section{INTRODUCTION}

Chromoblastomycosis (CBM) is defined as a chronic cutaneous and subcutaneous fungal infection resulting from traumatic implantation of certain dematiaceous fungi through the skin. The infection typically results from traumatic injury and inoculation of dematiaceous fungi, such as Fonsecaea pedrosoi, Phialophora verrucosa, or Cladophialophora carrionii. These fungi, which are predominantly present in tropical and subtropical regions, reside in the soil and on the surface of plants and typically infect humans following a trauma in the form of a laceration or puncture wound ${ }^{(1)}$. Although corneal ulcers due to F. pedrosoi have been reported, there are no reports of isolated conjunctival ulceration due to F. pedrosoi in the literature. This study reports a case in which the fungus F. pedrosoi was isolated from a conjunctival ulcer that was caused by a penetrating trauma.

\section{CASE REPORT}

A 30-year-old Syrian male patient presented to our emergency service complaining of penetration of an iron spike in his right eye. On examination, visual acuity was 20/30 in the right eye and 20/20 in the left eye. A full-thickness, fragmented, 3- $\mathrm{mm}$ corneal penetration at the 5 o'clock position of the cornea of the right eye and iris prolapse were detected. Multiple foreign bodies in the conjunctiva were observed. Under general anesthesia, all foreign bodies in the conjunctiva, the cornea, and prolapsed iris tissue were removed. Following iris repositioning, the corneal laceration was repaired with a 10/0 nylon suture. Then, $0.1 \mathrm{ml}$ of $0.5 \%$ moxifloxacin was introduced in the anterior chamber. Gentamicin and dexamethasone were subconjunctivally administered. The procedure was completed without complications.

The conjunctiva of the right eye was hyperemic on the first postoperative day. Topical moxifloxacin and prednisolone acetate were initiated for prophylactic purposes. On postoperative day 2, two foci of white purulent secretions both sized $2 \times 2 \mathrm{~mm}$, which were 3-4 $\mathrm{mm}$ from the limbus at the 5 and 7 o'clock positions, were observed (Figure 1). Fungal conjunctivitis was suspected in light of the injury from an iron spike, presence of a white purulent discharge in the conjunctiva, and hygiene conditions of the patient. A swab for culture was obtained from the conjunctival ulcer secretion. Steroid treatment was terminated, and topical amphotericin B was initiated at a dose of $0.2 \mathrm{mg} / \mathrm{ml}, 12$ times per day. On postoperative day 4, an excision was performed because of persistent conjunctival secretions despite topical treatment. A microbiological sample was again obtained prior to surgery. The two foci of purulent secretions at the 5 and 7 o'clock positions, which were $4 \mathrm{~mm}$ from the limbus, were excised as a whole, and the sample was sent for pathological evaluation. The patient had continuing secretions from the focus at the wound edge following surgical excision and also reported pain.

Pathological examination revealed findings of chronic granulomatous inflammation. On microbiological examination, flat, heaped, folded, green-colored colonies were initially observed on Sabouraud dextrose agar (Oxoid, Hampshire, England) before the colonies returned to a deep black olive-green color with black reverse (Figure 2). To identify the causative species, samples were sent to the Public Health Institution of Turkey Mycology Reference Laboratory (PHIT-MRL).
Submitted for publication: April 10, 2015

Accepted for publication: October 20, 2015

Department of Ophthalmology, Harran University School of Medicine, Sanliurfa, Turkey.

2 Mycology Reference Laboratory, Public Health Institution of Turkey, Ankara, Turkey.

${ }^{3}$ Department of Medical Microbiology, Harran University School of Medicine, Sanliurfa, Turkey.
Funding: No specific financial support was available for this study

Disclosure of potential conflicts of interest: None of the authors have any potential conflicts of interest to disclose.

Corresponding author: Fatih Mehmet Adibelli. Harran University Medical School. Department of Ophthalmology. Yenisehir Kampusu, Sanliurfa 63100 - Turkey - E-mail: fadibelli@gmail.com 
Species identification was performed at PHIT-MRL. After 14 days of incubation at $25^{\circ} \mathrm{C}$ in Sabouraud dextrose agar and potato dextrose agar (PDA; Oxoid, Hampshire, England), brown-black pigmented colonies, which are typical characteristics of dematiaceous fungi, were observed (Figure 2).

On microscopic examination of slides that were stained with lactophenol cotton blue, cylindrical conidiophores with slightly swollen terminal located denticles, giving rise to single-celled primary conidia, were observed among black, septate hyphae (Figure 3). The causative fungus was difficult to identify because of low conidiogenesis but was eventually identified by slide culture as F. pedrosoi(2).

Distinction from other molds that grow in brown-black colonies was performed according to the presence of melanin pigments in the cell wall of the dematiaceous fungi. Macroscopic and microscopic morphology with typical conidial head appearance and temperature and duration of growth were concurrently evaluated. Fonsecaea species was differentiated from Cladophialophora species according to the presence of short conidial chains (five or less conidia), from Rhinocladiella species through the lack of an Exophiala synanamorph, and from F. compacta through the lack of compact clusters of darker conidiophores with round conidia and septate cells.

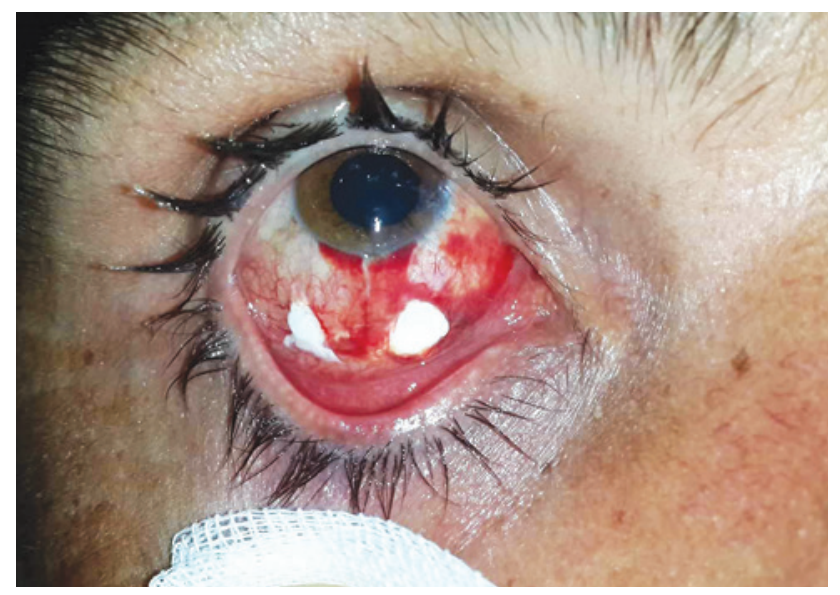

Figure 1. Appearance of the conjunctival ulcer on postoperative day 2.

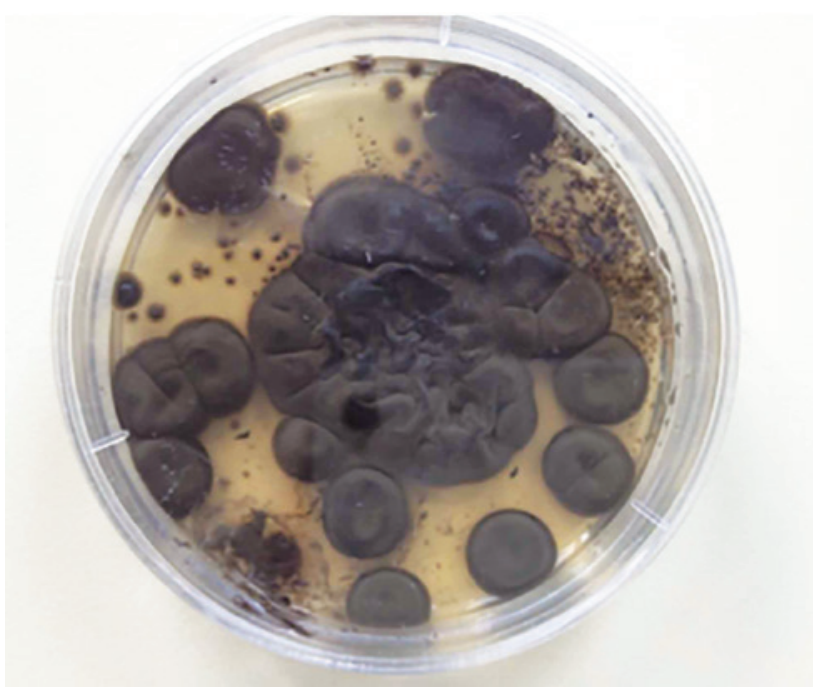

Figure 2. Surface appearance of the dusky fungus colony in PDA.
In addition to excisional biopsy, topical combination therapy of amphotericin B $(0.5 \mathrm{mg} / \mathrm{mL})$ drops and $100 \mathrm{mg}$ oral itraconazole tablets was administered twice daily, with $2 \mathrm{mg} / \mathrm{ml}$ fluconazole subconjunctivally applied twice daily. Conjunctival secretions completely cessated after 3 weeks, and the complaints of pain subsided. Visual acuity improved to 20/20 following treatment.

\section{DISCUSSION}

To the best of our knowledge, this is the first case of an isolated conjunctival ulcer due to acute F. pedrosoi infection reported in the literature.

Fonsecaea species represent a type of a dusky fungus, which is particularly present in the soil and roots of trees. F. pedrosoi is the most common cause of chromoblastomycosis worldwide ${ }^{(2)}$. Many infections develop in humans secondary to trauma. Infections may result from the inoculation of hypha and conidia during traumatic injury. Clinical lesions are characterized by erythema, papules, nodules, and verrucous plaques and/or ulcerations ${ }^{(3)}$. Histopathological evaluations in this case demonstrated chronic granulomatous inflammation supporting the clinical diagnosis of fungal infection ${ }^{(4)}$ Previous reports of ophthalmological disease secondary to F. pedrosoi infection are rare in the literature ${ }^{(5,6)}$. Chronic cases of conjunctivitis due to dirty-white and green-colored conjunctival chromoblastomycosis have been previously reported ${ }^{(7)}$. Conjunctival secretions in this case were white in color and were excised on postoperative day 4. Cultured swab material obtained changed color after day 7 and became greenish black. Several diseases and causative organisms should be considered in the differential diagnosis of conjunctival ulcer, including melanoma, Behçet's disease, Crohn's disease, fungal infections, herpes simplex, syphilis, and tuberculosis. Therefore, histopathological and mycological identifications are cornerstones of the diagnosis and treatment of F. pedrosoi conjunctivitis ${ }^{(6,8)}$.

Excisional biopsy in addition to antifungal agents is recommended in cases of infection with melanized fungi because of a greater resistance to an antifungal treatment ${ }^{(5)}$. Standard treatment regimens have yet to be reported; however, a number of authors have reported the use of itraconazole as the treatment of choice in dermatological cases $^{(9,10)}$. It has also been demonstrated that subconjunctival fluco-

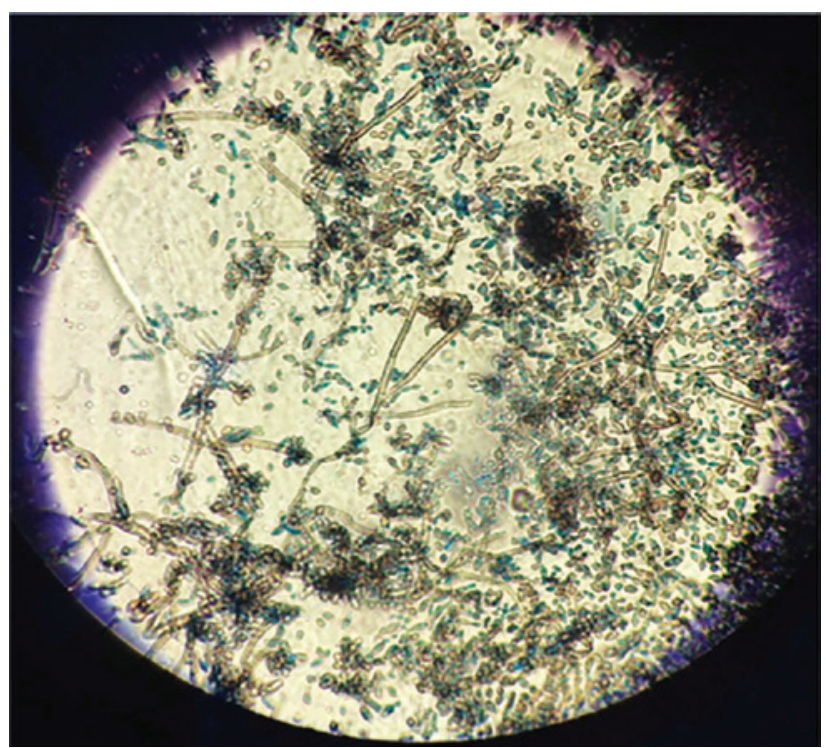

Figure 3. Micromorphological appearance of a corneal ulcer swab sample following lactophenol cotton blue staining. 
nazole $(2 \mathrm{mg} / \mathrm{mL})$ injections are more effective compared with topical amphotericin $B(0.5 \mathrm{mg} / \mathrm{mL})$ only in the treatment of fungal keratitis. In this case, we decided to administer topical amphotericin B, oral itraconazole, and subconjunctival fluconazole injection subsequent to surgical excision according to previously reported approaches.

F. pedrosoi should be considered in the differential diagnosis of painful lesions with secretions that are non-healing despite standard antibiotic treatment following contaminated trauma. Appropriate culture techniques for the growth of F. pedrosoi should be added to microbiological examinations in such cases.

\section{REFERENCES}

1. Lopez Martinez R, Mendez Tovar LJ. Chromoblastomycosis. Clinics in dermatology. 2007:25(2):188-94

2. Larone $\mathrm{DH}$, editor. Medically important fungi: A guide to identification. $4^{\text {th }}$ ed. Washington, D.C.: American Society for Microbiology Press; 2002. p.179-86.

3. de Sousa Mda G, Belda W Jr., Spina R, Lota PR, Valente NS, Brown GD, et al. Topical application of imiquimod as a treatment for chromoblastomycosis. Clin I Infect Dis. 2014;58(12):1734-7.

4. Nimrichter L, Cerqueira MD, Leitao EA, Miranda K, Nakayasu ES, Almeida SR, et al. Structure, cellular distribution, antigenicity, and biological functions of Fonsecaea pedrosoi ceramide monohexosides. Infect Immun. 2005;73(12):7860-8.

5. Hofling-Lima AL, Guarro J, Freitas D, Godoy P, Gene J, Souza LB, et al. Clinical treatment of corneal infection due to Fonsecaea pedrosoi--case report. Arq Bras Oftlamol. 2005;68(2):270-2.

6. Bui AQ, Espana EM, Margo CE. Chromoblastomycosis of the conjunctiva mimicking melanoma of the ciliary body. Arch Ophthalmol. 2012;130(12):1615-7.

7. Sangwan J, Lathwal S, Juyal D, Sharma N. Fonsecaea pedrosoi: a rare etiology in fungal keratitis. J Clin Diag Res. 2013;7(10):2272-3.

8. Roy FH, editor. Ocular differential diagnosis. $9^{\text {th }}$ ed. Panama: JP Medical; 2012. p.184.

9. Azevedo CD, Bruna-Romero O, Marques SG, Nascimento FR, Pinto MC, Silva LA, et al. Association of lgG immunoglobulin and subclasses level with the severity of chromoblastomycosis due to Fonsecaea pedrosoi and therapeutic response to itraconazole. Eur J Clin Microbiol Infect Dis. 2014;33(10):1791-7.

10. Gupta AK, Taborda PR, Sanzovo AD. Alternate week and combination itraconazole and terbinafine therapy for chromoblastomycosis caused by Fonsecaea pedrosoi in Brazil. Med Mycol. 2002;40(5):529-34 